\title{
Growth of N-substituted polypyrrole layers in ionic liquids: Synthesis and its electrochromic properties
}

\author{
Shahzada Ahmad ${ }^{\mathrm{a}, *}$, Songul Sen Gursoy ${ }^{\mathrm{b}}$, Samrana Kazim ${ }^{\mathrm{c}}$, Aysegul Uygun ${ }^{\mathrm{d}}$ \\ ${ }^{a}$ Electronic Materials Division, National Physical Laboratory, Dr. K.S. Krishnan Road, New Delhi-110012, India \\ ${ }^{\mathrm{b}}$ Mehmet Akif Ersoy University, Faculty of Arts and Science, Department of Chemistry, Burdur 15100, Turkey \\ ' Institute of Macromolecular Chemistry, ASCR, v.v.i, Heyrovsky Square 2, 16206 Prague 6, Czech Republic \\ d Suleyman Demirel University, Faculty of Arts and Science, Department of Chemistry, Isparta 32260, Turkey
}

\section{A R T I C L E I N F O}

Available online 22 October 2011

Keywords:

Polypyrrole

Substituted polypyrrole

Ionic liquids

Electropolymerization

Electrochromism

\section{Introduction}

Among the various heterocycle-based conjugated polymers, such as azulenes, furans, pyrroles, thiophenes and others, polypyrrole (PPy) is one of the most studied conducting polymer and has received attention due to unusual electrical, optical and electrochemical properties [1]. Owing to its environmental stability, high electrical conductivity, ease of synthesis by chemical as well as electrochemical route, film forming ability and biocompatibility, PPy has been used in chemical sensors, photovoltaics, actuators, electrochemical cells [2-4], biological applications $[5,6]$ and electrochromic devices $[7,8]$. In spite of the many advantages of PPy, insolubility, brittleness and non-processability are some of the drawbacks of PPy, which can be easily addressed by appending a variety of substituent or fused rings into the main chain [9-13]. This structural control leads to the optimization of properties such as solution processability, better electronic conductivity and stability of polymer under environmental condition. Hence, to protect N-position in PPy by the appropriate substituent is a facile approach, which will introduce novel synergistic properties i.e. structural changes with enhanced solubility and processability.

\footnotetext{
* Corresponding author. Current address: Max Planck Institute for Polymer Research, Ackermannweg 10 D-55128 Mainz, Germany. Tel.: +496131 379115; fax: +496131379310 .

E-mail addresses: shahzada80@gmail.com, ahmad@mpip-mainz.mpg.de (S. Ahmad).
}

Due to the ease of formation of relatively stable radical cations (polarons), N-substituted pyrrole readily polymerizes by oxidative polymerization chemically or electrochemically $[9,14]$. As a consequence, solubility and functionality of resulting polymers can be further improved. However, thin films obtained at liquid or solid interface by chemical oxidation were found with inferior quality $[15,16]$ and to prepare adherent and uniform thin polymer films of controlled thickness directly at the electrode surface, electrodeposition is found to be cost effective and is a one step process. As a matter of fact, electrodeposition process mainly employs classical salt-solvent based electrolytes, which induces unknown changes in the microstructure by the hydrophobicity and high vapor pressure of the solvent. This results in less electrochemical stability, poor adherence with the substrate and less environmental benignity [17].

Room temperature ionic liquids, are known to be environmentally benign media and ready to use hydrophobic electrolytes, can be exploited for the growth of PPy films [3,4,17-21] due to their non-volatility and excellent electrochemical stability. Ionic liquids owing to their outstanding range of properties are known to show considerable enhancement in reaction kinetics and selectivity for processing in comparison to its counterparts derived from conventional liquid electrolyte. They provide an advantageous alternative to aqueous media, as their large potential window facilitate the deposition of polymers and metals that are otherwise inaccessible in aqueous or organic solvents. The synthesis of $\pi$-conjugated polymers in ionic liquids has demonstrated improved stability and increased lifetime. The inherent 
properties of ionic liquids such as high conductivity, wide potential window and air/moisture stability make them easy alternatives as chemically mild, stable electrolytes in the development of electrochemical and electrochromic (EC) devices [22]. With the use of acetonitrile, the deposition efficiency decreases as the film grows and the rate of electrodeposition is significantly faster in the ionic liquid than conventional non-polar solvents.

Conjugated polymers exhibit a change in their optical spectra when they are exposed to a dopant. The fact that conjugated polymers can repeatedly undergo electrochemical doping/undoping processes makes them a promising class of material to be used in EC devices with wide hue of colors. These $\pi$-conjugated polymers offer support for the incorporation of ionic liquids into a variety of electrochemical materials and their reversible doping/ undoping processes make them suitable for application in electrochromic devices [21-26]. In contrast, PPy has received much less attention than polyaniline and poly(3,4-ethylenedioxythiophene) and other conjugated polymers due to the poor EC properties and $\alpha, \beta$ coupling [27]. Since the oxidized state of the PPy is black, the application of the PPy for EC devices is limited. One alternative to utilize the PPy as electrochromes is the use of $\mathrm{N}$-substituted PPy, to induce specific properties in polymer. Thus, functionalization offers possibility to develop materials that show behavior resulting from the combination of properties due to the conjugated backbone (electronic properties) and the functional groups.

To tune the properties of parent PPy for electroactive and EC application, we report here a series of promising monomer, which has not been reported so far, distinguished by ortho(o-), meta(m-) and para(p-) position of alkyl group and the synthesis of corresponding polymer. N-substituted PPy shows different morphologies and conductivity according to the position of methyl group on the benzene ring and synthesis medium. The obtained conductivity values of polymers are in the range of semiconductive materials, i.e. $>10^{-5} \mathrm{~S} / \mathrm{cm}$. An expedient means of the preparation and electrochemical, optical along with morphological properties of a series of $\mathrm{N}$-(methyl)phenyl pyrroles electropolymerized in ionic liquids is discussed.

\section{Experimental}

\subsection{Synthesis and structural characterization of monomers}

1-(2-methylphenyl)-1H-pyrrole, 1-(3-methylphenyl)-1H-pyrrole and 1-(4-methylphenyl)-1H-pyrrole: $26.5 \mathrm{ml}$ glacial acetic acid and substituted toluidine (o-toluidine, m-toluidine and p-toluidine) ( $0.059 \mathrm{~mol})$ were agitated using a magnetic stirring device and 2,5-dimethoxytetrahydrofuran $(0.059 \mathrm{~mol})$ was then added slowly to this mixture (10-15 min). The solution was refluxed for one hour under heating. When the color change from red to black was observed, acetic acid was removed from the solution with the aid of micro distillation setup. The residue, dark colored precipitate, was crystallized. The IR, ${ }^{1} \mathrm{H}-\mathrm{NMR}$ and ${ }^{13} \mathrm{C}$ NMR results of monomers were given as follows:

1-(2-methylphenyl)-1H-pyrrole: (B.P: $203{ }^{\circ} \mathrm{C}$, yield: 74\%) IR $\left(V_{\max } \mathrm{KBr}\right): 670 \mathrm{~cm}^{-1}$ (C-H bending), $1040 \mathrm{~cm}^{-1}$ (benzene), $1070-1200 \mathrm{~cm}^{-1}$ (aromatic $\mathrm{C}-\mathrm{H}$ bending), $1325 \mathrm{~cm}^{-1}$ (C-H bending (alkene)), $1440-1461 \mathrm{~cm}^{-1}$ ( $\mathrm{CH}_{3}$ bending), $1504 \mathrm{~cm}^{-1}$ (aromatic), $1581 \mathrm{~cm}^{-1}$ ( $\mathrm{C}=\mathrm{C}$ stretching), $2860 \mathrm{~cm}^{-1}$ (aliphatic C$\mathrm{H}$ stretching), $3029-3068 \mathrm{~cm}^{-1}$ (aromatic C-H stretching), $3129 \mathrm{~cm}^{-1}$ (C-H stretching (alkene)). ${ }^{1} \mathrm{H}-\mathrm{NMR}: J_{\mathrm{Ha}-\mathrm{Hb}}$ : ortho$8.52 \mathrm{~Hz}, J_{\mathrm{Ha}-\mathrm{Hc}}$ : meta- $2.28 \mathrm{~Hz}, \mathrm{Ha}: 7.39 \mathrm{ppm}$; J J $\mathrm{Hb}-\mathrm{Ha}$ : ortho$7.62 \mathrm{~Hz}, J_{\mathrm{Hb}-\mathrm{Hc}}$ : ortho- $7.60 \mathrm{~Hz}, J_{\mathrm{Hb}-\mathrm{Hd}}$ : meta- $2.30 \mathrm{~Hz}, \mathrm{Hb}: 7.50$ ppm; $J_{\mathrm{Hc}-\mathrm{Hb}}$ : ortho- $7.42 \mathrm{~Hz}, J_{\mathrm{Hc}-\mathrm{Hd}}$ : ortho- $8.23 \mathrm{~Hz}, J_{\mathrm{Hc}-\mathrm{Ha}}$ : meta-
$2.01 \mathrm{~Hz} \mathrm{Hc}$ : $6.9 \mathrm{ppm}, J_{\mathrm{Hd}-\mathrm{Hc}}$ : ortho- $6.72 \mathrm{~Hz}, J_{\mathrm{Hd}-\mathrm{Hb}}$ : meta- $2.72 \mathrm{~Hz}$, Hd: $7.15 \mathrm{ppm}$; He:2.25 ppm specific doublet peak, belongs to pyrrole $H \alpha$ : 6.9 ppm specific triplet peak; $H \beta$ : 6.45 ppm specific triplet peak.

${ }^{13}$ C-NMR: 134.05 ppm (C5), 130.79 ppm (C7), $127.82 \mathrm{ppm}$ (C10), 122.67 ppm (C9), $122.32 \mathrm{ppm}$ (C8), $119.11 \mathrm{ppm}$ (C1-C3), 115.45 ppm (C6), 109.29 ppm (C2-C4), 17.67 ppm (C11).

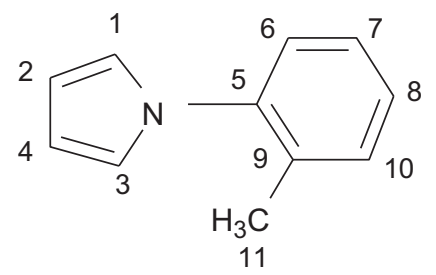

1-(3-methylphenyl)-1 H-pyrrole: (B.P: $245{ }^{\circ} \mathrm{C}$, Yield: 69\%) IR $\left(V_{\max } \mathrm{KBr}\right): 691 \mathrm{~cm}^{-1}$ (C-H bending), $1033 \mathrm{~cm}^{-1}$ (benzene), $1071-1089 \mathrm{~cm}^{-1}$ (aromatic $\mathrm{C}-\mathrm{H}$ bending), $1322 \mathrm{~cm}^{-1}(\mathrm{C}-\mathrm{H}$ bending (alkene)), $1452 \mathrm{~cm}^{-1}\left(\mathrm{CH}_{3}\right.$ bending), $1501 \mathrm{~cm}^{-1}$ (aromatic), $1592 \mathrm{~cm}^{-1}$ ( $\mathrm{C}=\mathrm{C}$ stretching), $2865 \mathrm{~cm}^{-1}$ (aliphatic $\mathrm{C}-\mathrm{H}$ stretching), $3040 \mathrm{~cm}^{-1}$ (aromatic C-H stretching), $3136 \mathrm{~cm}^{-1}(\mathrm{C}-$ $\mathrm{H}$ stretching (alkene)).

${ }^{1} \mathrm{H}-\mathrm{NMR}: J_{\mathrm{Ha}-\mathrm{Hb}}$ : meta- $1.97 \mathrm{~Hz}, J_{\mathrm{Ha}-\mathrm{Hd}}$ : ortho- $7.84 \mathrm{~Hz}$, Ha: $7.21 \mathrm{ppm}$; $J_{\mathrm{Hb}-\mathrm{Ha}}$ : meta- $1.62 \mathrm{~Hz}, J_{\mathrm{Hb}-\mathrm{Hc}}$ : ortho- $8.42 \mathrm{~Hz}, J_{\mathrm{Hb}-\mathrm{Hd}}$ : meta- $1.97 \mathrm{~Hz}, \mathrm{Hb}$ : $7.48 \mathrm{ppm}$; $J_{\mathrm{Hc}-\mathrm{Hb}}$ : ortho- $6.72 \mathrm{~Hz}, J_{\mathrm{Hc}-\mathrm{Hd}}$ : ortho- $8.38 \mathrm{~Hz}$, Hc: $7.50 \mathrm{ppm}, J_{\mathrm{Hd}-\mathrm{Hc}}$ : ortho- $7.81 \mathrm{~Hz}, J_{\mathrm{Hd}-\mathrm{Hb}}$ : meta$2.87 \mathrm{~Hz}, \mathrm{H}_{\mathrm{d}}-\mathrm{H}_{\mathrm{a}}$ meta- $1.83 \mathrm{~Hz}, \mathrm{H}_{\mathrm{d}}: 7.25 \mathrm{ppm} ; \mathrm{H}_{\mathrm{e}}: 2.25 \mathrm{ppm}$ specific doublet peak, belongs to pyrrole $\mathrm{H} \alpha$ : 7.19 ppm specific triplet peak; $H \beta$ : 6.43 ppm specific triplet peak.

${ }^{13}$ C-NMR: $140.92 \mathrm{ppm}$ (C5), $139.67 \mathrm{ppm}$ (C10), $129.54 \mathrm{ppm}$ (C7), 126.57 ppm (C8), 121.40 ppm (C1-C3), 119.49 ppm (C6), 117.80 ppm (C9), 110.49 ppm (C2-C4), 21.66 ppm(C11).

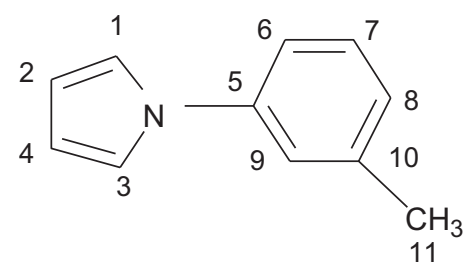

1-(4-methylphenyl)-1 H-pyrrole: (Yield: 66\%): IR ( $\left.V_{\max } \mathrm{KBr}\right)$ : $718 \mathrm{~cm}^{-1}$ (C-H bending), $1013 \mathrm{~cm}^{-1}$ (benzene), $1072 \mathrm{~cm}^{-1}$ (aromatic $\mathrm{C}-\mathrm{H}$ bending), $1323 \mathrm{~cm}^{-1}$ ( $\mathrm{C}-\mathrm{H}$ bending), $1474 \mathrm{~cm}^{-1}\left(\mathrm{CH}_{3}\right.$ bending), $1523 \mathrm{~cm}^{-1}$ (aromatic), $1599 \mathrm{~cm}^{-1}$ ( $\mathrm{C}=\mathrm{C}$ stretching), $2859 \mathrm{~cm}^{-1}$ (aliphatic C-H stretching), $3036 \mathrm{~cm}^{-1}$ (aromatic C-H stretching), $3141 \mathrm{~cm}^{-1}$ (C-H stretching (alkene)).

${ }_{-}^{1} \mathrm{H}-\mathrm{NMR}: J_{\mathrm{Ha}-\mathrm{Hb}}$ : ortho- $7.36 \mathrm{~Hz}, \mathrm{H}_{\mathrm{a}}: 6.41 \mathrm{ppm}, J_{\mathrm{Hb}-\mathrm{Ha}}$ : meta$2.04 \mathrm{~Hz}, \mathrm{H}_{\mathrm{b}}$ : $7.45 \mathrm{ppm}$; $\mathrm{H}_{\mathrm{e}}$ : $2.25 \mathrm{ppm}$ specific doublet peak, belongs to pyrrole $\mathrm{H} \alpha$ : $7.1 \mathrm{ppm}$ specific triplet peak; $\mathrm{H} \beta$ : $6.35 \mathrm{ppm}$ specific triplet peak.

${ }^{13}$ C-NMR: 138.50 ppm (C5), $135.40 \mathrm{ppm} \mathrm{(C8),} 129.53 \mathrm{ppm}$ (C7-C10), $120.56 \mathrm{ppm}$ (C1-C3), $119.42 \mathrm{ppm} \quad$ (C6-C9), 110.09 ppm (C2-C4), 20.89 ppm (C11).

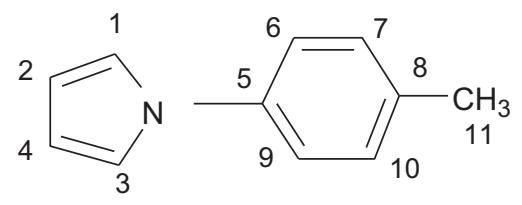

\subsection{Deposition of the polymer films}

1-ethyl-3-methylimidazolium bis(pentafluoroethylsulfonyl)imide (EMIPFSI) was synthesized according to the reported 
a<smiles>Cc1ccccc1-n1cccc1</smiles>

b

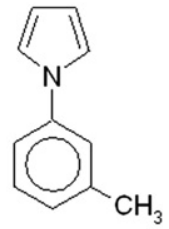

C<smiles>Cc1ccc(-n2cccc2)cc1</smiles>

Fig. 1. Chemical structure of the ortho, meta and para N-(methyl)phenyl pyrrole (monomer) used in this study.

method [22] and was mixed with $0.1 \mathrm{M}$ monomer (Fig. 1). EMIPFSI is a Bronsted acid-base ionic liquid, containing perfluorinated side chain as anion ( $\mathrm{PFSI}^{-}$) makes them hydrophobic and has affinity toward $\mathrm{O}_{2}$. Films were also grown galvanostatically onto conducting substrate $\left(\mathrm{SnO}_{2}: \mathrm{F}\right.$ coated glass) as anode at room temperature $\left(25 \pm 2{ }^{\circ} \mathrm{C}\right)$ in a glass cell including a Pt sheet as the cathode by passing current of $0.3 \mathrm{~mA} / \mathrm{cm}^{2}$ for 5 min under controlled environment. The substrates were cleaned ultrasonically prior to use, using deionized water, acetone and ethyl alcohol sequentially. In the text ortho, meta and para $\mathrm{N}$-(methyl)phenyl polypyrroles will be now refered to as NoMPhPPy, NmMPhPPy and NpMPhPPy, respectively. For comparison, NoMPhPPy films were also grown in control media consisting of a $0.25 \mathrm{M} \mathrm{LiCF}_{3} \mathrm{SO}_{3}$ (Aldrich) in acetonitrile (Merck) with $0.1 \mathrm{M}$ monomer. After the polymerization, the film was removed from growth solution, washed with isopropyl alcohol to get rid of any unreacted monomer as well as ionic liquids.

\subsection{Characterization of the polymer films}

FTIR spectra of the samples were recorded in the transmission mode at room temperature on a Perkin-Elmer spectrometer (HP91QA, UK) in the range of $400-4000 \mathrm{~cm}^{-1}$ with resolution of $4 \mathrm{~cm}^{-1} .{ }^{1} \mathrm{H}$ - and ${ }^{13} \mathrm{C}$-NMR spectra were recorded on Bruker using $\mathrm{CDCl}_{3}$ as a solvent. Conductivity measurements were carried out using a PCI-DAS6014 (Measurement Computing) as a current source, voltammeter and temperature controller following a standard four point probe method. UV-Vis absorption measurements were recorded with a Perkin Elmer, Lambda 900 spectrophotometer while the contact angle measurements were carried out by the Sessile drop method using a drop shape analyzer (DSA 100, DSA/V 1.9) from Kruss Gmbh. Scanning probe microscopy (SPM) microscopy (SPM) images were recorded in intermittent contact mode (Dimension 3100, Veeco), by using Si-probes OMCL 160TS (Olympus, cantilever having a nominal spring constant $42 \mathrm{Nm}^{-1}$ and a resonance frequency of $300 \mathrm{kHz}$ ). Electrochemical characterizations of samples were carried out in the three-electrode cell equipped with a Gamry potentiostat (Gamry Instruments). The platinum disk or conducting glass substrates were used as working electrodes, platinum wire and $\mathrm{Ag} / \mathrm{AgCl}$ electrodes were used as counter and reference electrodes, respectively. Alumina polishing suspension agglomerate $(0.05 \mu \mathrm{m}$ CR) (Baikowski) was used as electrode polisher. Scanning electron microscopy images were recorded on Phillips XL-30S FEG, while transmission electron microscope (TEM) images were recorded on a Philips CM-10 instrument, and the samples were extracted onto carbon coated copper grids using $\mathrm{N}$-methyl pyrrolidine and dried before use.

\section{Results and discussion}

\subsection{Electrochemical studies}

The growth of polymers was studied by cyclic voltammograms at a scan rate $50 \mathrm{mV} / \mathrm{s}$ (Supporting Info. S1). These voltammograms illustrate characteristic polymerization graphics and with the increase in the polymerization cycles the color of the polymer turned from yellow to brown-black on the electrode surface after thirty cycles (Fig. S2). The anodic oxidation peak was obtained about $1.5 \mathrm{~V}$ vs. $\mathrm{Ag} / \mathrm{AgCl}$ for the control media (Fig. S1a), while this value was lowered by $150 \mathrm{mV}$ to about $1.35 \mathrm{~V}$ for ionic liquids (Fig S1b), due to the low surface potential of ionic liquids in the polymerization process [28]. After thirty scans cycle the polymer coated modified electrode was rinsed to remove the monomer and oligomer residues and dried. Fig. 2 shows the redox properties of the $\mathrm{N}$-substituted polypyrroles films in monomer free EMIPFSI and the oxidation potentials shift to higher values, which indicate the polymerization of $\mathrm{N}$-substituted pyrroles [29]. The polymer films shows high electroactivity in EMIPFSI. Inset of
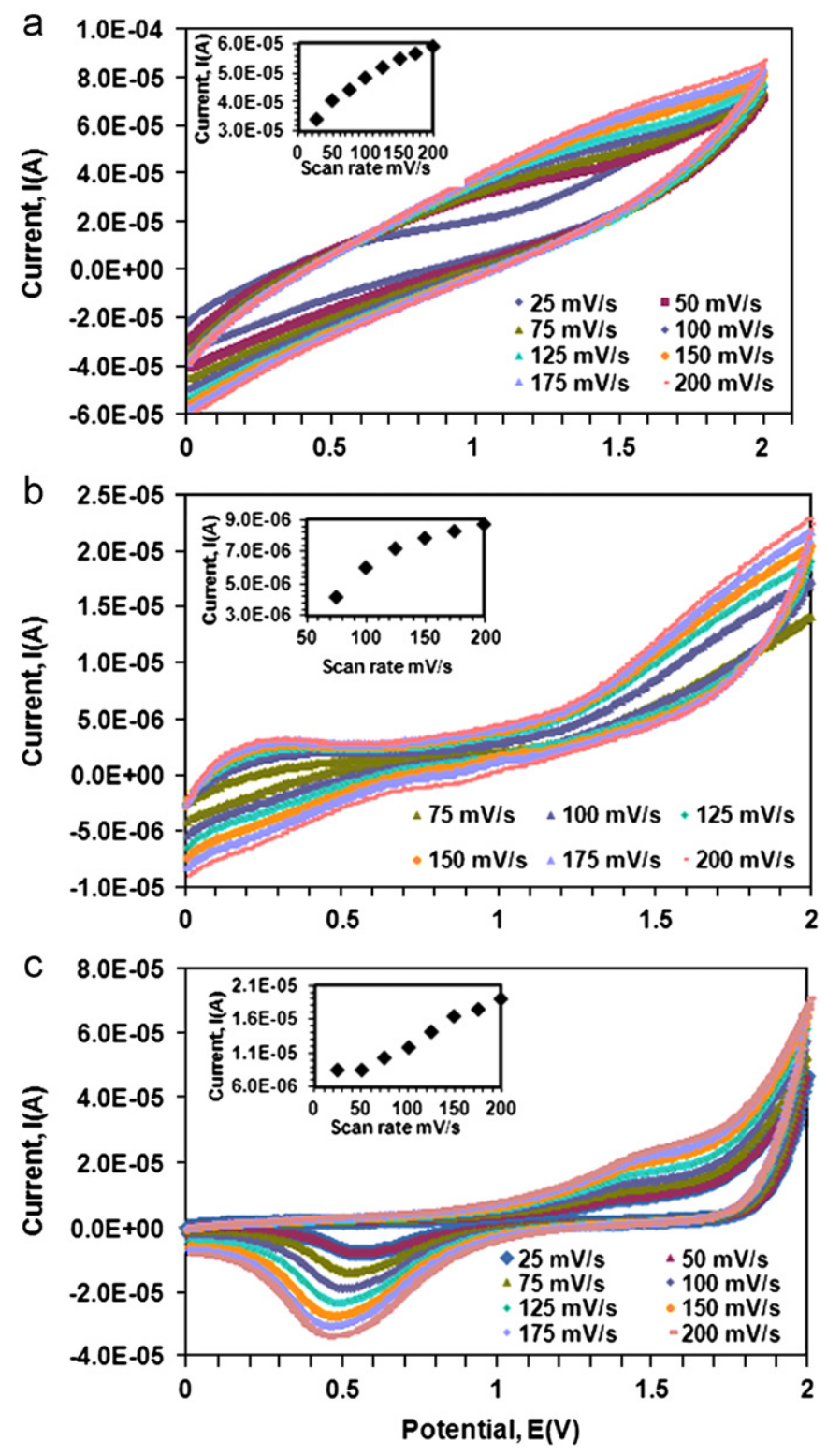

Fig. 2. Redox properties of polymer films in EMIPFSI at various scan rates (25-200 mV/s) for (a) NoMPhPPy, (b) NmMPhPPy and (c) NpMPhPPy. 
Fig. 1a-c shows a linear increase in the anodic peak current density as a function of the scan rate pointing towards the redox reaction in these films is diffusion limited. The redox activity of the polymer films remains fairly constant and it follows the reversible redox couples as observed during the cycling.

\subsection{FTIR of $N$-substituted polypyrroles}

FTIR spectra of the electropolymerized NoMPhPPy synthesized in two media is distinct, the one which is prepared in ionic liquids exhibits less water uptake, are shown in Fig. 3(a-b). The observed bands from FTIR spectra of N-(methyl)phenyl pyrroles are characteristic bands for pyrrole and phenyl rings, and they are very similar to each other. The sharp peak at around $1574 \mathrm{~cm}^{-1}$ is one of the characteristic bands of pyrrole ring while the absorption band at $1458 \mathrm{~cm}^{-1}$ is attributed to the in plane $=\mathrm{CH}$ stretching vibrations of pyrrole and phenyl rings [30]. The peaks appeared in the range of 1223 and $1089 \mathrm{~cm}^{-1}$ are the signature peaks for pyrrole rings [31] while the absorption bands at 742-743, 977-978 and 1086-1088 $\mathrm{cm}^{-1}$ correspond to $\mathrm{C}-\mathrm{H}$ stretching of $\mathrm{N}$-substituted pyrroles. The weak bands that appeared to be around $2980 \mathrm{~cm}^{-1}$ were attributed to alkyl groups for N-substituted PPy, while the appearance of band around $790 \mathrm{~cm}^{-1}$ was distinctive of substituted five-member heterocyclic compound indicates $\alpha$-coupling of ring. The peaks at around 839, and $643 \mathrm{~cm}^{-1}$ in the spectra of $\mathrm{N}$-(methyl)phenyl pyrroles were assigned to the out-of-plane vibration of three adjacent carbonhydrogen bonds in the spectrum reflect the substituted benzene ring [32]. FTIR spectra of the NoMPhPPy synthesized in two media have also indicated difference in the peak around $1033 \mathrm{~cm}^{-1}$. This peak is characteristic, $\mathrm{SO}_{3}$ stretching vibration showing the presence of $\mathrm{LiCF}_{3} \mathrm{SO}_{3}$ as doping anion [33].

\subsection{Scanning probe microscopy (SPM)}

SPM measurements were performed to have an idea of root mean square (RMS) roughness and phase contrast on these different $\mathrm{N}$-(methyl)phenyl polypyrrole films. Small granules like structures were observed from SPM in contrast to large granules (cauliflower) like morphology that is characteristics of PPy. These synthesized $\mathrm{N}$-(methyl)phenyl substituted polypyrrole films shows nanoparticulate structure having size of $>100 \mathrm{~nm}$, which was also observed from TEM images (Supporting info. S3). Topography of these films (Fig. 4) exhibits homogeneous morphologies and the size of grains are fairly affected from the

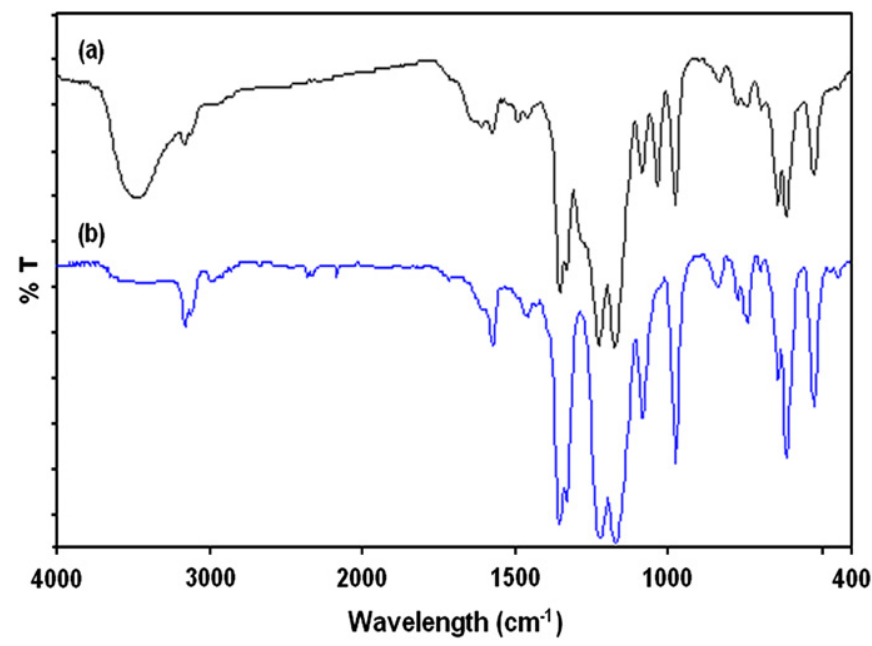

Fig. 3. FTIR spectra of (a) NoMPhPPy in control solution and (b) NoMPhPPy in ionic liquids. position of methyl group in the polymer backbone. These granules become larger by shifting the methyl group from $\mathrm{o}-$ to $\mathrm{m}$ - to p- positions due to steric effect.

The RMS roughness value of these films was found to be of $12 \pm 0.5 \mathrm{~nm}$ estimated on an area of $1 \times 1 \mu \mathrm{m}^{2}$. The phase contrast recorded at the scale of $1 \times 1 \mu \mathrm{m}^{2}$ did not reveal a significant contrast (Fig. $4 a^{\prime}$ ) thus the substrate is covered entirely with the polymer film of uniform deformability. By varying the position of substituent, the film morphologies differ significantly. The small grain size will increase the surface area of polymer films and might facilitate ion immobilization and mass diffusion at solid/ liquid interface, and thus improve the performance of the electrodes for electrocatalytic properties. The high surface area coverage and continuous film formation properties for the films deposited in ionic liquids might be potentially useful for sensor and other applications.

$\mathrm{N}$-substituted PPy are known to demonstrate conductivity of many orders of magnitude lower than that of PPy. Table 1 represents the conductivity value for different substituents of alkyl group in phenyl polypyrrole. The electrical conductivity and oxidation level of the 1-alkyl-substituted polypyrroles decreases with increasing size of the alkyl substituent as substituents give rise to modifications in polymer film properties [34]. Thus, while PPy films can demonstrate a conductivity value of upto $100 \mathrm{~S} / \mathrm{cm}$, poly-1-(methyl)pyrrole has a conductivity of $10^{-3} \mathrm{~S} / \mathrm{cm}$, and here we have observed that $\mathrm{N}$-(methyl)phenyl polypyrroles show conductivity in the range of $>10^{-5} \mathrm{~S} / \mathrm{cm}$. Due to the large size of the substituent at the nitrogen atom, the steric interaction between the repeating units will be higher and results in lower conductivity. We speculate that the substituents alter the polymer conductivity solely via a steric effect. The substituent effects exerted by $\mathrm{N}$-(p-methyl)phenyl pyrrole are much more subtle than 1-substituted pyrroles since the electronic substituent effect is first transmitted through a phenyl ring before the pyrrole structure is affected and thus has a lower conductivity among all the three substituents. Furthermore, if the phenyl ring is twisted relative to the pyrrole moieties, the substituent effect is further diluted. Thus, the substituent effect is expected to be rather modest, and this has been observed. The ionic liquids based samples show increase in the conductivity value than control one, which may be attributed due to the imidazolium cation, which also incorporate into polymer matrix when ionic liquids is used as a medium for electropolymerization.

The contact angle value reveals the hydrophobic/hydrophillic character of the surface. The use of ionic liquids makes the polymer more hydrophobic and the position of methyl group also has a bearing on the hydrophobicity of polymer. NpMPhPPy shows higher contact angle value, which illustrates its hydrophobicity among o- and m- position alkyl group.

\subsection{UV-Vis spectra}

The absorption maxima in the spectra of $\mathrm{N}$-methylphenyl pyrroles were shifted to the higher wavelength from monomers, shows that the conjugation is increasing when polymerization is realized. Since PPy is strongly colored in both doped-undoped states and its contrast ratio is too low for the fabrication of practical EC devices. The electrochromic properties (Fig. 5) of the $\mathrm{N}$-(methyl)phenyl polypyrrole films were analyzed ex-situ in liquid electrolytes ( $1 \mathrm{M} \mathrm{LiCF}_{3} \mathrm{SO}_{3}$ in acetonitrile). The maximum absorbance in oxidized state is shown by the p-substituted followed by o-substituted (methyl)phenyl polypyrrole, which shows absorbance in photopic wavelengths at 356 and $318 \mathrm{~nm}$, respectively, while the m-substituent shows up at $314 \mathrm{~nm}$ and the film produced in a conventional lithium triflate-acetonitrile solution shows the lowest. All the polymers film exhibit different 

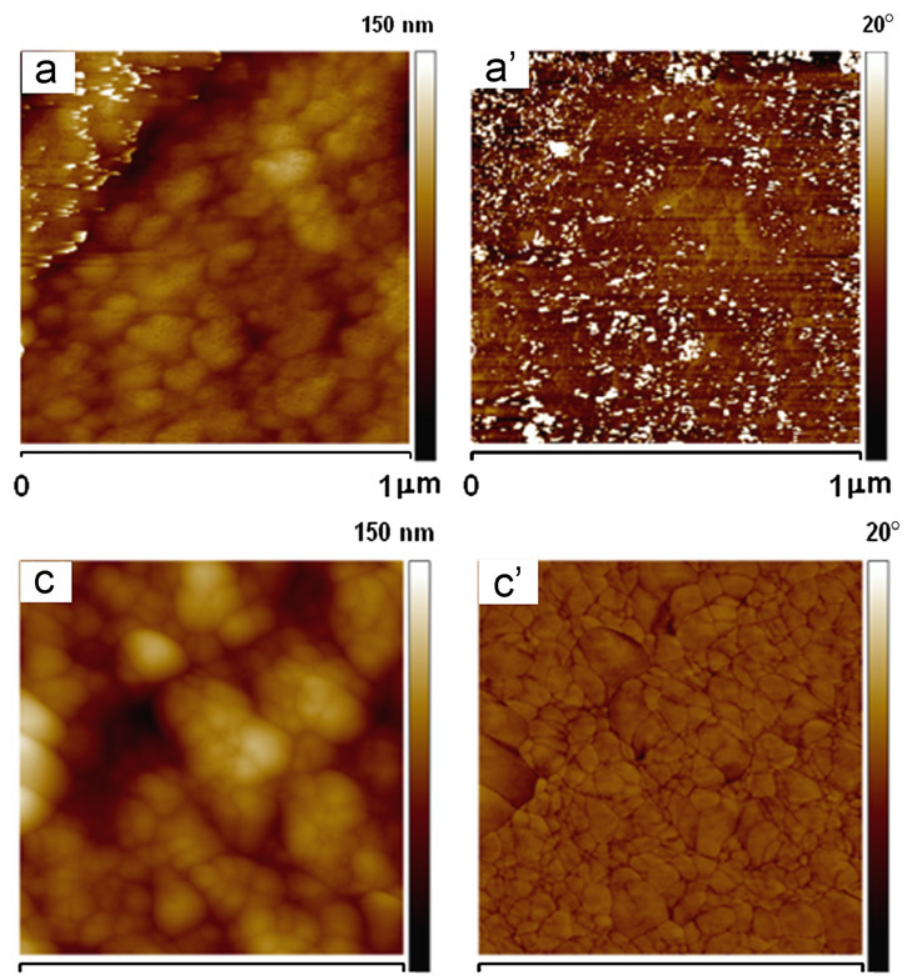

0
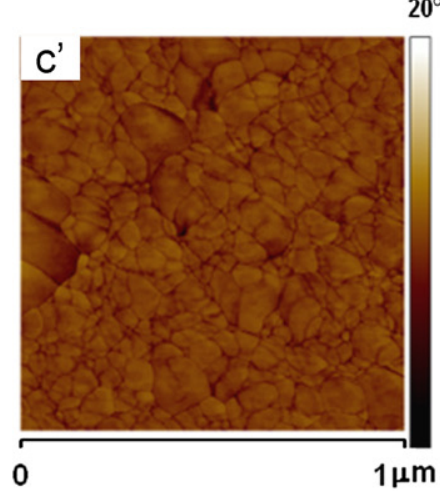

$1 \mu \mathrm{m}$ $20^{\circ}$
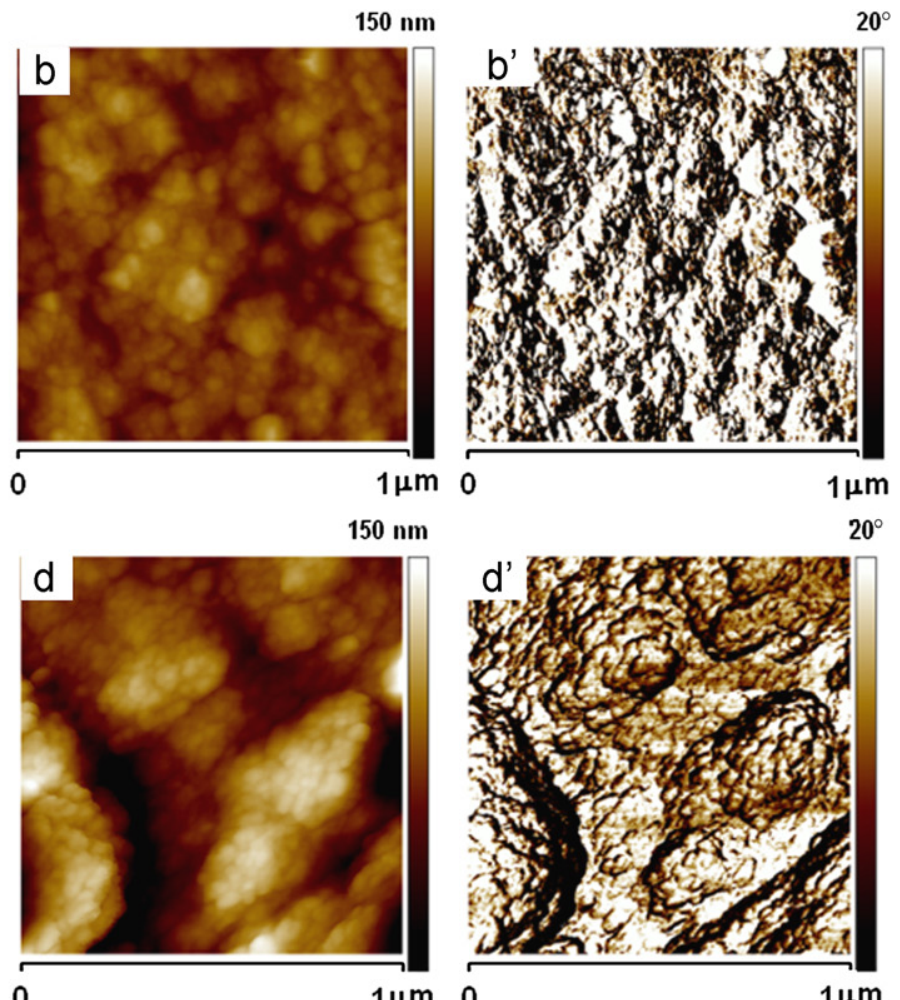

$1 \mu \mathrm{m}$

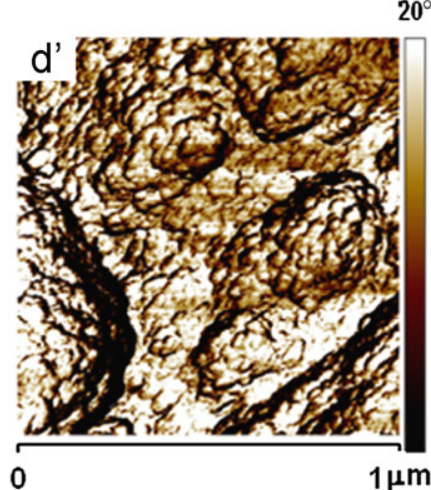

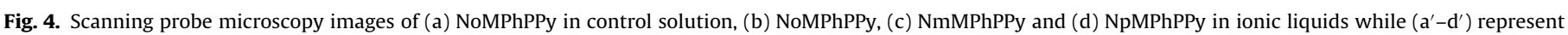
the corresponding phase images.

Table 1

Conductivity and contact angle value for various substituted $\mathrm{N}$-(methyl)phenyl polypyrrole.

\begin{tabular}{lcl}
\hline Sample & Conductivity (S/cm) & Contact angle \\
\hline NoMPhPPy (control solution) & $6 \times 10^{-5}$ & 58.1 \\
NoMPhPPy (ILs) & $9 \times 10^{-5}$ & 60.4 \\
NmMPhPPy(ILs) & $5.2 \times 10^{-5}$ & 62 \\
NpMPhPPy(ILs) & $1.2 \times 10^{-5}$ & 64 \\
\hline
\end{tabular}

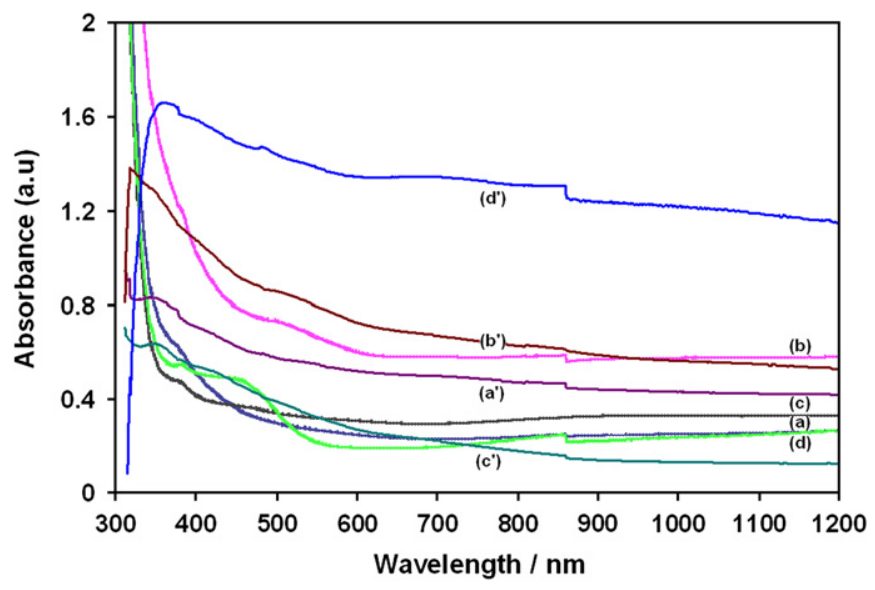

Fig. 5. Absorption spectra of (a) NoMPhPPy in control solution, (b) NoMPhPPy, (c) NmMPhPPy and (d) NpMPhPPy in ionic liquids as synthesized in colored state and $\left(\mathrm{a}^{\prime}-\mathrm{d}^{\prime}\right)$ the corresponding oxidized state obtain by passing $1.5 \mathrm{~V}$ for $60 \mathrm{sec}$.

$\pi-\pi^{*}$ transition as the $\lambda_{\max }$ value is shifting with the o-, m- and p-position. The NpMPhPPy exhibits maximum change in transmission from colored to bleached state and demonstrate relatively lower band gap as can be observed from $\pi-\pi^{*}$ transition in oxidized state. The UV-Vis absorption in the neutral state shows a broad peak between $400-500 \mathrm{~nm}$, which corresponds to the transitions from valence band to the anti-bonding polaron state. As the extent of oxidation increases, bipolaron formation increases. The presence of bipolarons leads to only two optical transitions in the gap, which explains the appearance of absorption spectra at higher oxidation levels. All these films can be switched between the reduced (dark brown) to oxidized state. The absorption peak observed between 310 and 350 is assigned to $\pi-\pi^{*}$ transition associated with phenyl ring. At the neutral state due to the $\pi-\pi^{*}$ transitions, $\lambda_{\max }$ for PPy (Fig. 5) was found to be starting at around $390 \mathrm{~nm}$. N-substituents in the PPy give rise to a nano-particulate structure, where this unique geometry will facilitate ion extraction and injection along with better charge retention properties.

\section{Conclusions}

o-,m- and p-, (methyl)phenyl pyrrole has been synthesized by an easy synthetic approach and then electropolymerized to obtain a new series of PPy family by direct anodic oxidation in a hydrophobic ionic liquid. FTIR and UV-Visible optical results show that the spectra of the $\mathrm{N}$-(methyl)phenyl polypyrroles are affected from the position of methyl group. $\mathrm{N}$-(methyl)phenyl polypyrroles show different morphologies and conductivity according to the position of methyl group on the benzene ring and synthesis medium. The conductivity values of these polymers are in the range of semi conductive materials, i.e. $>10^{-5} \mathrm{~S} / \mathrm{cm}$. These new series of $\mathrm{N}$-(methyl)phenyl polypyrroles also exhibit switching properties, i.e. color change from golden brown to gray on an application of small dc voltage. Compact and adherent thin film was obtained, which exhibits good electrocatalytic activity 
and stability. We believe that these polymers will pave way for the development of new materials with potential application.

\section{Supporting information available}

Cyclic voltammetry growth of polymers in different media, transmission and scanning electron microscope images and FTIR of polymers.

\section{Acknowledgments}

One of us (SA) gratefully acknowledges Hans-Jürgen Butt and Rüdiger Berger for their support in SPM measurements and to the Alexander von Humboldt-Foundation for the financial support.

\section{Appendix A. Supplementary material}

Supplementary data associated with this article can be found in the online version at doi:10.1016/j.solmat.2011.09.049.

\section{References}

[1] T.A. Skotheim, R.L. Elsenbaumer, J.R. Reynolds, Handbook of Conducting Polymers, 2nd ed., Marcel Dekker, New York, 1998.

[2] H.K. Song, G.T.R. Palmore, Redox-active polypyrrole: toward polymer based batteries, Advanced Materials 18 (2006) 1764-1768.

[3] J.M. Pringle, J. Efthimiadis, P.C. Howlett, J. Efthimiadis, D.R. MacFarlane, A.B. Chaplin, S.B. Hall, D.L. Officer, G.G. Wallace, M. Forsyth, Synthesis of polypyrrole in ionic liquids, Polymer 45 (2004) 1447-1453.

[4] Y. Berdichevsky, Y.-H. Lo, Polypyrrole nanowire actuators, Advanced Materials 18 (2006) $122-125$

[5] C.A. Thomas, K. Zong, P. Schottland, J.R. Reynolds, Poly(3,4 alkylenedioxypyrrole)s as highly stable aqueous-compatible conducting polymers with biomedical implications, Advanced Materials 12 (2000) 222-225.

[6] A.N. Zelikin, D.M. Lynn, J. Farhadi, I. Martin, V. Shastri, R. Langer, Erodible conducting polymers for potential biomedical applications, Angewandte Chemie. International Edition 41 (2002) 141-144.

[7] M. Shibata, K.I. Kawashita, R. Yosomiya, Z. Gongzheng, Electrochromic properties of polypyrrole composite films in solid polymer electrolyte, European Polymer Journal 37 (2001) 915-919.

[8] S. Ahmad, S. Singh, Electrochromic device based on carbon nanotubes functionalized poly (methyl pyrrole) synthesized in hydrophobic ionic liquid medium, Electrochemistry Communications 10 (2008) 895-898.

[9] G. Zotti, S. Zecchin, G. Schiavon, B. Vercelli, A. Berlin, S. Grimoldi, Poly(Nhexyl-cyclopenta[c]pyrrole)—A novel 1,3,4-alkyl-substituted polypyrrole soluble in organic solvents and redox conducting, Macromolecular Chemistry and Physics 205 (2004) 2026-2031.

[10] E.E. Havinga, W.T. Hoeve, E.W. Meijer, H. Wynberg, Water-soluble self-doped 3-substituted polypyrroles, Chemistry of Materials 1 (1989) 650-659.

[11] J.R. Reynolds, N.S. Sundaresan, M. Pomerantz, S. Basak, C.K. Baker, Self-doped conducting copolymers: a charge transport study of poly\{pyrrole-co-[3(pyrrol-1-yl)propanesulfonate]\}, Journal of Electroanalytical Chemistry 250 (1988) 355-371.

[12] G. Sonmez, I. Schwendeman, P. Schottland, K. Zong, J.R. Reynolds, $\mathrm{N}$-substituted poly(3,4-propylenedioxypyrrole)s: high gap and low redox potential switching electroactive and electrochromic polymers, Macromolecules 36 (2003) 639-647.
[13] H. Masuda, S. Tanaka, K. Haeriyama, Soluble conducting polypyrrole: poly(3octylpyrrole), Journal of the Chemical Society, Chemical Communications (1989) 725-726.

[14] R.M. Walcak, J.H. Jung, J.S. Cowart, J.R. Reynolds, 3,4-alkylenedioxypyrrolebased conjugated polymers with finely tuned electronic and optical properties via a flexible and efficient $\mathrm{N}$-functionalization method, Macromolecules 40 (2007) 7777-7785.

[15] G.B. Street, T.C. Clarke, M. Krounbi, K.K. Kanazawa, V. Lee, P. Pfluger, J.C. Scott G. Weiser, Preparation and characterization of neutral and oxidized polypyrrole films, Molecular Crystals \& Liquid Crystals 83 (1982) 253-264.

[16] M. Salmon, K.K. Kanazawa, A.F. Diaz, N. Krounbi, A Chemical Route to Pyrrole Polymer, Journal of Polymer Science. Polymer Letters Ed. 20 (1982) 187-193.

[17] J.M. Pringle, M. Forsyth, G.G. Wallace, D.R. MacFarlane, Solution-surface electropolymerization: a route to morphologically novel poly(pyrrole) using an ionic liquid, Macromolecules 39 (2006) 7193-7195.

[18] S. Ahmad, R. Berger, H.U. Khan, H.-J. Butt, Electrical field Assisted growth of poly(3-hexylthiophene) layers employing ionic liquids: microstructure elucidated by scanning force and electron microscopy, Journal of Materials Chemistry 20 (2010) 5325-5334.

[19] R. Marcilla, C. Pozo-Gonzalo, C. Rodriguez, JA Alduncin, J.A. Pomposo, D. Mercerreyes, Use of polymeric ionic liquids as stabilizers in the synthesis of polypyrrole organic dispersions, Synthetic Metals 156 (2006) 1133-1138.

20] K. Sekiguchi, M. Atobe, T. Fuchigami, Electropolymerization of pyrrole in 1-ethyl-3-methylimidazolium trifluoromethanesulfonate room temperature ionic liquid, Electrochemistry Communications 48 (2002) 81-85.

[21] M. Deepa, S. Ahmad, Polypyrrole films electropolymerized from ionic liquids and in a traditional liquid electrolyte: a comparison of morphology and electro-optical properties, European Polymer Journal 44 (2008) 3288-3299.

[22] W. Lu, A.G. Fadeev, B.H. Qi, E. Smela, J. Ding, G.M. Spinks, J. Mazurkiewicz D. Zhou, G.G. Wallace, D.R. MacFarlance, S.A. Forsyth, M. Forsyth, Use of ionic liquids for pi-conjugated polymer electrochemical devices, Science 297 (2002) 983-987

23] W. Lu, A.G. Fadeev, B.H. Qi, B.R. Mattes, Fabricating conducting polyme electrochromic devices using ionic liquids, Journal of Electrochemical Society 151 (2004) H33-H39.

[24] Y.H. Pang, H. Xu, X.Y. Li, H.L. Ding, Y.X. Cheng, G.Y. Shi, L.T. Jin, Electrochemical synthesis, characterization, and electrochromic properties of poly(3-chlorothiophene) and its copolymer with 3-methylthiophene in a room temperature ionic liquid, Electrochemistry Communications 8 (2006) 1757-1763.

[25] M. Dobbelin, C. Pozo-Gonzalo, R. Marcilla, R. Blanco, J.L. Segura, J.A. Pomposo, D. Mecerreyes, Electrochemical synthesis of PEDOT derivatives bearing imidazolium-ionic liquid moieties, Journal of Polymer Science PART A: Polymer Chemistry 47 (2009) 3010-3021.

[26] D.X. Zhuang, P.Y. Chen, Electrochemical formation of polycarbazole films in air- and water-stable room-temperature ionic liquids, Journal of Electroanalytical Chemistry 626 (2009) 197-200.

[27] M.K. Ram, N.S. Sundaresan, H. Vardhan, B.D. Malhotra, Electrochromic response of thin polypyrrole film in semi-solid electrolyte, Journal of Materials Science Letters 15 (1996) 997-1000.

[28] S. Ahmad, T. Carstens, R. Berger, H.-J. Butt, F. Endres, Surface polymerization of (3,4-ethylenedioxythiophene) probed by using scanning tunneling microscope on Au (111) in ionic liquids, Nanoscale 3 (2011) 251-257.

[29] B. Duran, M.C. Turhan, G. Bereket, A.S. Sarac, Electropolymerization, characterization and corrosion performance of poly(N-ethylaniline) on copper, Electrochimica Acta 55 (2009) 104-112.

[30] V.L. Colvin, M.C. Schlamp, A.P. Alivisatos, Light emitting diodes made from cadmium and a semiconducting polymer, Nature 370 (1994) 354-357.

[31] M.V. Kulkarni, A.K. Viswanath, U.P. Mulik, Studies on chemically synthesized organic acid doped poly(o-toluidine), Materials Chemistry and Physics 89 (2005) 1-5.

[32] B. Lu, J. Xu, C. Fan, F. Jiang, H. Miao, Facile electrosynthesis of nitro-group substituted oligopyrene with bicolored emission, Electrochimica Acta 54 (2008) 334-340.

[33] S. Ramesh, L.J. Yi, FTIR spectra of plasticized high molecular weight PVC$\mathrm{LiCF}_{3} \mathrm{SO}_{3}$ electrolytes, Ionics 15 (2009) 413-420.

[34] A.F. Diaz, J. Castillo, K.K. Kanazawa, J.A. Logan, M. Salmon, O. Fajardo Conducting poly-N-alkylpyrrole polymer films, Journal of Electroanalytica Chemistry 133 (1982) 233-239. 